\title{
Research on Ease of Protective Clothing Based on Three-dimensional Human Body Scanning *
}

\author{
Ming-Ming Feng ${ }^{\mathrm{a}}$, Li Liu ${ }^{\mathrm{a}, *}, \mathrm{Hui}_{\mathrm{Z}}{ }^{\mathrm{a}}{ }^{\mathrm{a}}$ Xiao-Hui Zheng ${ }^{\mathrm{b}}$, Xiao-Chen $\mathrm{Li}^{\mathrm{a}}$ \\ ${ }^{a}$ Beijing Institute of Fashion Technology, No.2 Yinghua Road Chaoyang District, Beijing, China \\ ${ }^{\mathrm{b}}$ State Key Laboratory of NBC Protection for Civilian, Research Institute of Chemical Defense \\ Beijing, China
}

\begin{abstract}
The experiment recruited 18 young healthy males as the subjects. Four postures with a limited range of movement during outdoor activity were captured by the mean of a 3D scanning system. The grids of rows and columns were made on the skin surface before scanning. The grids' distance in terms of skin stretch was measured between the static posture and the four experimental postures. A paired sample T-test was conducted to test that the variation in skin length change for each part of the body. Among them, there were more significant changes in the horizontal direction for the small shoulder width, back width, bust, hip, thigh circumference, knee circumference, big arm circumference and elbow circumference. In the vertical direction, except for the inner lines of the legs, all measured sizes changed significantly. Through further analysis, it was found that the back length and the back width were relatively active factors that affected the entire upper limb movement. Finally, according to the changes in the measured sizes, it is necessary to explore protective clothing in terms of ease.
\end{abstract}

Keywords: Protective Clothing; 3D Scanning System; Skin Stretch; Ease Design

\section{Introduction}

A special type of clothing, protective clothing, is highly important in the field of life-saving and safety protection. But, in addition to comfort, the mobility of protective clothing should meet the wearer's need. However, there are some problems in the structure and size of clothing [1], which affect the wearing comfort, but also the safety of the wearer. Therefore, it is necessary to study the ease of protective clothing.

Current research emphasizes the structure design of the protective clothing. Xiang-Hui Zhang [2] proposed the method of "concurrent engineering" to design the structure of protective clothing. Huck [3] studied the crotch of one-piece protective clothing. He added ease at the waist to satisfy

${ }^{\star}$ Project supported by Beijing Key Laboratory of Clothing Ergonomics and Innovation Functional Design program (KYTG02170202).

${ }^{*}$ Corresponding author.

Email address: fzyll@bift.edu.cn (Li Liu). 
the minimum amount during squatting. Mullet [4] found that the structure of a protective suit influences the movement function of the human body, but also the clothing thermal comfort. But there is no research on the overall structure of protective clothing [5-12]. This paper used 3D scanning [13] technology to discuss the skin stretching of different postures and provided some suggestions for ease design [14] in terms of protective clothing.

\section{Experiment}

\subsection{Experimental Subjects}

The subjects of the experiment were 18 young healthy males aged 20-25 years, with a height of $170-180 \mathrm{~cm}$ and a BMI of 18 to 25 .

Table 1: Basic information on experimental subjects

\begin{tabular}{ccccccc}
\hline Subject Number & Height $(\mathrm{cm})$ & Weight $(\mathrm{kg})$ & BMI $\left(\mathrm{kg} / \mathrm{m}^{2}\right)$ & Bust $(\mathrm{cm})$ & Waist $(\mathrm{cm})$ & Hip $(\mathrm{cm})$ \\
\hline No. 1 & 173.4 & 63.3 & 20.1 & 90.2 & 73.4 & 92.2 \\
No. 2 & 179.7 & 60.2 & 19.9 & 91.9 & 70.1 & 90.0 \\
No. 3 & 175.0 & 65.4 & 21.4 & 98.4 & 73.5 & 90.6 \\
No. 4 & 175.1 & 68.3 & 22.3 & 90.9 & 77.2 & 97.0 \\
No. 5 & 177.8 & 57.5 & 19.6 & 85.4 & 70.2 & 87.3 \\
No. 6 & 171.5 & 55.1 & 18.7 & 87.0 & 71.7 & 90.2 \\
No. 7 & 175.1 & 60.9 & 19.0 & 91.3 & 73.9 & 93.5 \\
No. 8 & 174.8 & 62.6 & 20.3 & 96.8 & 76.0 & 93.1 \\
No. 9 & 172.8 & 71.1 & 22.0 & 96.9 & 80.1 & 98.4 \\
No. 10 & 177.1 & 62.4 & 20.8 & 86.8 & 73.5 & 90.6 \\
No. 11 & 174.0 & 63.9 & 20.8 & 89.5 & 75.3 & 89.6 \\
No. 12 & 179.1 & 65.6 & 21.4 & 96.1 & 77.2 & 101.0 \\
No. 13 & 177.3 & 63.7 & 21.3 & 92.5 & 77.1 & 96.1 \\
No. 14 & 177.0 & 67.2 & 22.9 & 93.7 & 80.6 & 93.4 \\
No. 15 & 175.8 & 68.0 & 23.2 & 89.1 & 78.9 & 98.8 \\
No. 16 & 171.2 & 64.6 & 20.6 & 97.2 & 74.4 & 92.7 \\
No. 17 & 171.2 & 66.2 & 20.9 & 93.3 & 79.6 & 93.7 \\
No. 18 & 171.3 & 67.1 & 22.9 & 94.9 & 75.3 & 94.0 \\
Mean. & 174.9 & 64.1 & 21.0 & 92.3 & 75.4 & 93.5 \\
St. dev. & 2.7 & 3.9 & 1.3 & 3.9 & 3.2 & 3.6 \\
\hline
\end{tabular}

\subsection{Experimental Environment}

The experiment was carried out in the Ergonomics Centre of the Beijing Institute of Fashion Technology. The laboratory temperature was controlled at $22 \pm 2.5^{\circ} \mathrm{C}$, and relative the humidity was controlled at $50 \pm 2.5 \%$. Each subject needed to put on lab pants and adapt to the laboratory 
environment half an hour earlier. The content and method of the experiment were explained to the subjects in advance and written consent forms were obtained from all of them.

\subsection{Markered Ponits and Lines}

According to ISO 8559-1989 "Garment Construction and Anthropometric Surveys: Body Dimensions" [15], there are 31 markers on the human body. The specific quantities and distribution locations are shown in Table 2. The basic measured lines and points are shown in Fig. 1.

Table 2: Anthropometric reference points

\begin{tabular}{ccccc}
\hline Neck and Shoulder & Shoulder to Waist & Waist to Hip & Arm & Leg \\
\hline Front Neck Point & Front Armpit Point & Belly Bump Point & Ulnar Point & Maximum Thigh Girth Point \\
Back Neck Point & Rear Armpit Point & Hip Point & Elbow Point & Knee Centre Point \\
Side Neck Point & Bust Point & & Radial Point & Medial Ankle Point \\
SP1 Point & Scapulae Point & & & External Ankle Point \\
& Waist point & & & \\
\hline
\end{tabular}
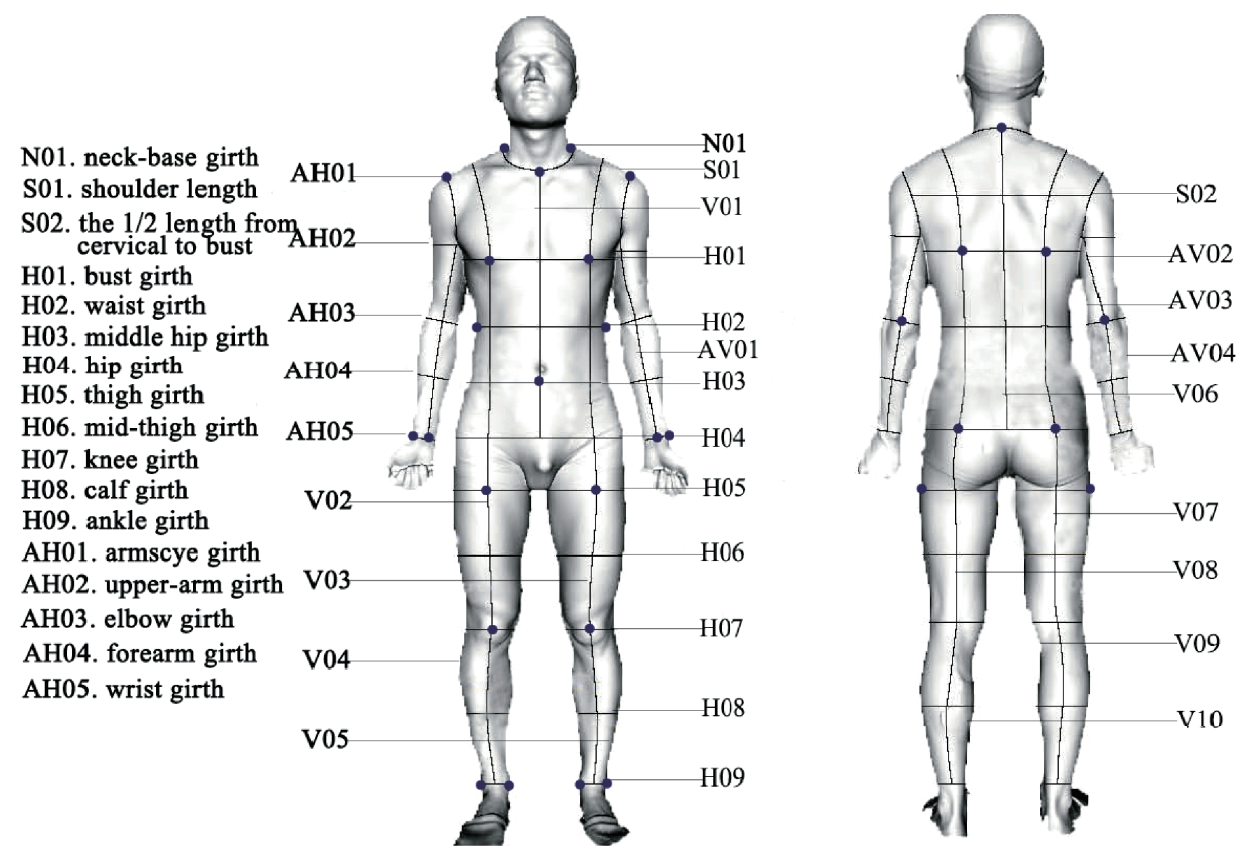

V01. front median length

V02. the length from $1 / 2$ of the right shoulder to ankle

V03. the length from $1 / 2$ of the

left shoulder to ankle

V04. the right lateral line of the body

V05. the left lateral line of the body

V06. rear median length

V07. the length from $1 / 2$ of the rigth shoulder to ankle

V08. the length from $1 / 2$ of the left shoulder to ankle

V09. inner length of right leg V10. inner length of left leg

AV01. front armpit point to wrist

AV02. rear armpit point to wrist

AV03. armpit point to wrist

AV04, arm length

Fig. 1: Measured lines of the human body

\subsection{Experimental Postures}

Four postures are selected based on the range of motion of the joint and the sizes of the garment required for plate-making. The four postures are maximum flexion of the arms, maximum flexion of the left leg, deep squat and hanging arms. Data on skin stretching resulting from the four postures help us to build a scientific understanding of motion ease design for protective suits. 


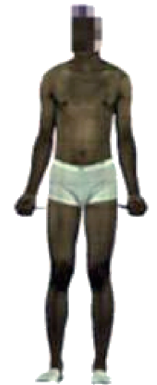

(a)

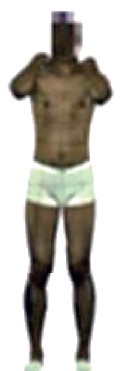

(b)

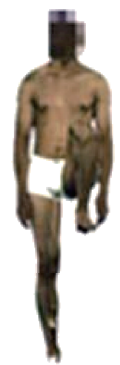

(c)

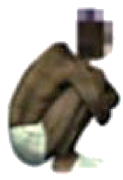

(d)

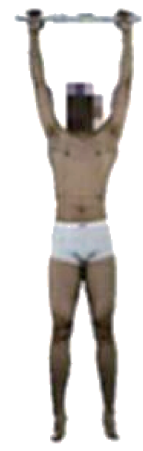

(e)

Fig. 2: (a) Static, (b) maximum flexion of the arms (c) maximum flexion of the left leg, (d) deep squat (e) hanging arms

\subsection{Experimental Methods}

First, the experiment used the ArtecEva non-contact hand-held 3D scanner and Nova Film's 3D camera matrix to obtain the data. The sizes changes of the human body were analysed by using the paired sample T-test. The change value and the rate of change are calculated by Formulas (1) and (2). The $v$ and $r$ values are the change value and the rate of change, respectively. The $l_{0}$ value is the length at the static posture. The $l$ value is the length at different postures.

$$
\begin{aligned}
& v(\mathrm{~cm})=l-l_{o} \\
& r(\%)=\frac{l-l_{0}}{l_{0}} \times 100 \%
\end{aligned}
$$

\section{Results and Discussion}

\subsection{Variation in Areas at Different Postures}

Table 3 shows the measured size changes in the horizontal and vertical directions of the human torso under different postures. It can be seen that the changes in the dimensions of the human torso are different at the same posture, and the variation in the sizes is different under different postures as well. Therefore, the physical requirements for protective clothing are also different under different postures. The paired sample T-test showed that, in terms of size changes in the horizontal direction, S01, S02, H01, H02, H04, H05, H06, H07, eight size changes were significant. In the vertical direction, the remaining size changes were significant, except for the legs inner lines V09 and V10.

The rate of change in the human torso areas is shown in Fig. 3. The expansion of the back is very common in daily life. In the horizontal direction, the back area's skin extends to its maximum value during squatting. S02 stretches reached $22.35 \%(7.84 \mathrm{~cm})$ and bust girth $\mathrm{H} 01$ stretches reached $16.88 \%(7.98 \mathrm{~cm})$. The stretching of the skin below the waist mainly occurs around the hip and knee joint. Hip girth H04, thigh girth H05, mid-thigh girth H06 and knee girth $\mathrm{H} 07$ all show a stretching trend, while the changes in calf girth and ankle girth are slight. Among them, hip girth H04 stretches reached $15.24 \%(7.17 \mathrm{~cm})$ and knee girth H07 stretches reached $20.48 \%(4.07 \mathrm{~cm})$. In terms of the vertical direction, most sizes show significant changes 
Table 3: Variation in the human torso areas at different postures (unit: $\mathrm{cm}$ )

\begin{tabular}{|c|c|c|c|c|c|}
\hline \multirow{2}{*}{\multicolumn{2}{|c|}{ Measured Sizes }} & \multicolumn{4}{|c|}{ Change Mean Value/Std.Error/P (Sig.) } \\
\hline & & $\mathrm{b}-\mathrm{a}$ & $\mathrm{c}-\mathrm{a}$ & $\mathrm{d}-\mathrm{a}$ & e-a \\
\hline \multirow{12}{*}{ Horizontal } & N01 & $-.182 / .042 / .776$ & $-.260 / .053 / .453$ & $-.726 / .112 / .087$ & $-.184 / .070 / .017$ \\
\hline & S01 & $-.353 / .045 / .085$ & $.338 / .094 / .002^{*}$ & $-1.422 / .175 / .000^{* *}$ & $-1.623 / .187 / .000^{* *}$ \\
\hline & S02 & $5.661 / .351 / .000^{* *}$ & $4.502 / .387 / .000^{* *}$ & $7.839 / .715 / .000^{* *}$ & $3.588 / .532 / .000^{* *}$ \\
\hline & H01 & $2.389 / .242 / .000^{* *}$ & $3.095 / .275 / .000^{* *}$ & $7.981 / .903 / .000^{* *}$ & $2.432 / .478 / .000^{* *}$ \\
\hline & H02 & $-.499 / .091 / .074$ & $.644 / .267 / .027$ & $2.422 / .324 / .000^{* *}$ & $1.210 / .267 / .000^{* *}$ \\
\hline & H03 & $-.604 / .540 / .279$ & $.791 / .413 / .073$ & $-.702 / .310 / / 074$ & $.772 / .284 / .015$ \\
\hline & H04 & $0.071 / .139 / .618$ & $4.922 / .411 / .000^{* *}$ & $7.167 / .524 / .000^{* *}$ & $-1.945 / .361 / .000^{* *}$ \\
\hline & H05 & $-.004 / .088 / .962$ & $3.135 / .440 / .000^{* *}$ & & $.830 / .140 / .000^{* *}$ \\
\hline & H06 & $-.062 / .087 / .487$ & $1.785 / .228 / .000^{* *}$ & & $-.756 / .382 / .064$ \\
\hline & H07 & $-.021 / .091 / .814$ & $4.074 / .370 / .000^{* *}$ & & $.666 / .214 / .006$ \\
\hline & H08 & $-.005 / .032 / .889$ & $.434 / .191 / .036$ & & $.247 / .296 / .416$ \\
\hline & H09 & $0.017 / .090 / .855$ & $.260 / .121 / .047$ & & $.274 / .139 / .066$ \\
\hline \multirow{10}{*}{ Vertical } & V01 & $.681 / .157 / .714$ & $-4.660 / .373 / .000^{* *}$ & & $7.587 / 1.009 / .000^{* *}$ \\
\hline & V02 & $.163 / .248 / .520$ & $.461 / .079 / .084$ & & $6.632 / .885 / .000^{* *}$ \\
\hline & V03 & $.099 / .097 / .324$ & $5.422 / .960 / .000^{* *}$ & & $6.810 / .882 / 000^{* *}$ \\
\hline & V04 & $.155 / .127 / .237$ & $-.298 / .064 / .996$ & $-.623 / .127 / .098$ & $9.455 / 1.453 / .000^{* *}$ \\
\hline & V05 & $.243 / .143 / .106$ & $-7.358 / .758 / .000^{* *}$ & $-.367 / .199 / .084$ & $8.560 / 1.683 / .000^{* *}$ \\
\hline & V01 & $-.901 / 282 / .005$ & $3.265 / .301 / .000^{* *}$ & $11.869 / .340 / .000^{* *}$ & $8.2851 .162 / .000^{* *}$ \\
\hline & V07 & $-.676 / .209 / .005$ & $.357 / .079 / .874$ & & $6.525 / .866 / .000^{* *}$ \\
\hline & V08 & $-.678 / .123 / .822$ & $6.244 / .838 .000^{* *}$ & & $6.988 / 1.085 / .000^{* *}$ \\
\hline & V09 & $-.066 / .255 / .799$ & $-.054 / .105 / .613$ & & $.101 / .718 / .890$ \\
\hline & V10 & $.074 / .326 / .824$ & $-.659 / .177 / .006$ & & $.081 / 1.211 / .947$ \\
\hline
\end{tabular}

Note: ' $*$ ' indicates a significant difference at the 0.05 level $(0.01 \leq p<0.05)$ and ' $* *$ ' indicates a highly significant difference at the 0.05 level $(p<0.01)$. '-' is reduced.

except for the inside legs lengths. Therefore, a detailed study of the sizes in the vertical direction is required.

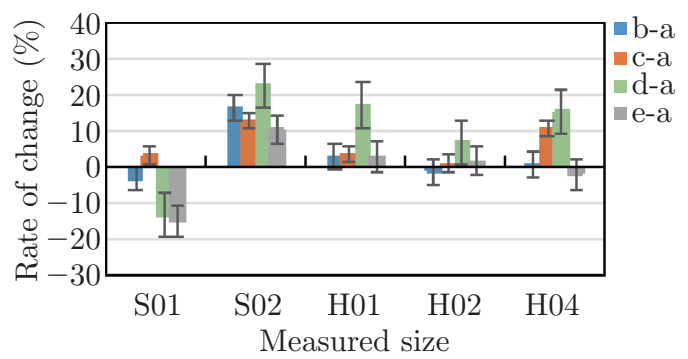

(a) The rate of change in the horizontal direction

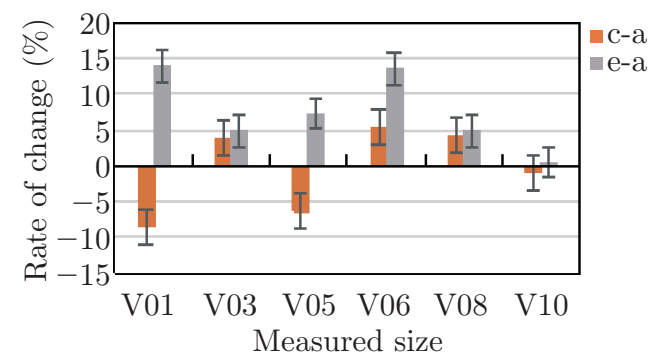

(b) The rate of change in the vertical direction

Fig. 3: The rate of change in the human torso areas

The arms are mainly forward and upward in daily life. Therefore, this paper only studies the forward and upward movements. Table 4 shows the change in the measured sizes of the arms 
under different postures. It can be seen that the size changes of the arms are different under the same posture. In the case of different postures, the change trends are also different. Among them, the horizontal sizes above the elbow change significantly. In the vertical direction, four sizes have varying degrees of change.

Table 4: Variation in arm areas at different postures (unit: $\mathrm{cm}$ )

\begin{tabular}{ccccc}
\hline \multirow{2}{*}{ Measured Sizes } & \multicolumn{3}{c}{ Change Mean Value/Std.Error/P(Sig.) } \\
\cline { 3 - 5 } & & b-a & d-a & e-a \\
\cline { 2 - 5 } Horizontal & AH01 & $1.197 / .188 / .000^{* *}$ & $1.491 / .297 / .000^{* *}$ & $-2.371 / .355 / .000^{* *}$ \\
& AH02 & $1.983 / .482 / .001^{*}$ & $1.160 / .172 / .000^{* *}$ & $.837 / .101 / .089$ \\
& AH03 & $3.273 / .303 / .000^{* *}$ & $1.983 / .191 / .000^{* *}$ & $-1.574 / .297 / .000^{* *}$ \\
& AH04 & $.259 / .243 / .301$ & $.357 / .104 / .003$ & $-1.075 / .201 / .000^{* *}$ \\
& AH05 & $.027 / .017 / .137$ & $.023 / .125 / .857$ & $-.345 / .042 / .454$ \\
\hline \multirow{6}{*}{ Vertical } & AV01 & $-5.757 / .704 / .000^{* *}$ & $-1.821 / .323 / .000^{* *}$ & $3.164 / .448 / .000^{* *}$ \\
& AV02 & $8.063 / .593 / .000^{* *}$ & $5.287 / 1.071 / .000^{* *}$ & $3.696 / .697 / 000^{* *}$ \\
& AV03 & $-3.739 / .457 / .000^{* *}$ & & $3.839 / .419 / .000^{* *}$ \\
& AV04 & $-7.178 / .898 / .000^{* *}$ & $-.545 / .632 / .401$ & $-3.847 / .494 / .000^{* *}$ \\
\hline
\end{tabular}

Note: ${ }^{(*)}$ indicates a significant difference at the 0.05 level $(0.01 \leq p<0.05)$ and ${ }^{(* *}$ ' indicates a highly significant difference at the 0.05 level $(p<0.01)$. '-' is reduced.

Fig. 4 shows the change rates of the arms in the horizontal and vertical directions under different postures. When the arms move forward, elbow girth AH03 stretches reached $23.55 \%(3.27 \mathrm{~cm})$ and the stretch rate of other horizontal sizes did not exceed $7.31 \%$. In the vertical direction, AV02 stretches reached $17.47 \%(8.06 \mathrm{~cm})$. The other sizes show a contraction trend. When the arms move up, the horizontal sizes of the arms basically show a contraction trend, and the change is little. The vertical sizes show a tendency of expansion except in the case of AV04. AV03 stretches reached $10.98 \%(3.84 \mathrm{~cm})$ and the stretch rate of the other sizes stretch did not exceed $8.01 \%$.

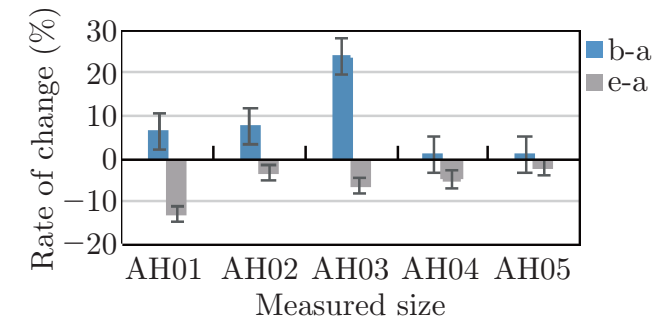

(a) The rate of change in the horizontal direction

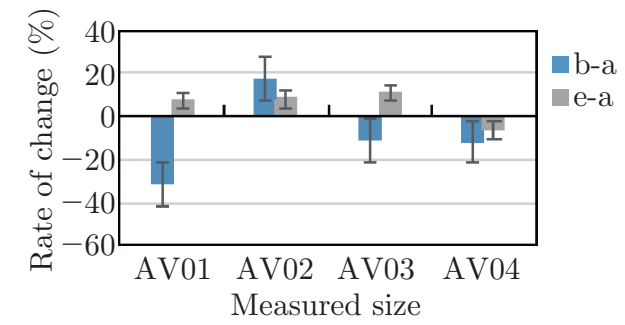

(b) The rate of change in the vertical direction

Fig. 4: The rate of change in the arm areas

\subsection{Vertical Sizes Change in the Upper and Lower Body}

Given the same change on the torso's left and right side in different postures, only the left torso is selected for study. Table 5 analyses the sizes change in the vertical direction of the overall human torso.The results are shown that back length and side length changing significantly. Back length 
Table 5: The vertical sizes change in the upper and lower body (unit: $\mathrm{cm}$ )

\begin{tabular}{lcccc}
\hline \multirow{2}{*}{ Measured Size } & \multicolumn{4}{c}{ Change Mean Value/Std.Error/P(Sig.) } \\
\cline { 2 - 5 } & $\mathrm{b}-\mathrm{a}$ & $\mathrm{c}-\mathrm{a}$ & $\mathrm{d}-\mathrm{a}$ & $\mathrm{e}-\mathrm{a}$ \\
\hline Back Length & $.148 / .184 / .433$ & $4.252 / .548 / .000^{* *}$ & $6.224 / .511 / .000^{* *}$ & $4.624 / .605 / .000^{* *}$ \\
Side Length & $1.806 / .304 / .000^{* *}$ & $-2.125 / .395 / / .000^{* *}$ & $.706 / .231 / .007$ & $4.249 / .515 / .000^{* *}$ \\
Outer Side Waist Length & $.854 / .184 / / .067$ & $-4.953 / .698 / .000^{* *}$ & $-1.683 / .207 / .000^{* *}$ & $5.330 / 1.273 / .001^{*}$ \\
Front Centre Line of & $.559 / .112 / .785$ & $4.920 / .430 / .000^{* *}$ & & $6.633 / 1.083 / .000^{* *}$ \\
$\quad$ & & & \\
$\quad$ Waist to Ankle & & & & $5.620 / .609 / .000^{* *}$ \\
Back Centre Line of & $-.807 / .211 / .056$ & $3.035 / .433 / .000^{* *}$ & & $1.095 / .275 / .001^{*}$ \\
$\quad$ Waist to Ankle & $.826 / .211 / .446$ & $-2.558 / 1.238 / .054$ & $-.981 / .147 / .005$ & $.824 / .268 / .007$ \\
Outer Length of Leg & $.235 / .049 / .995$ & $6.046 / .518 / .000^{* *}$ & & $.842 / .290 / .010$ \\
Front Centre Line of Leg & & & \\
Back Centre Line of Leg & $-.487 / .133 / .074$ & $1.076 / .289 / .002^{*}$ & & \\
\hline
\end{tabular}

Note: ${ }^{(*}$ ' indicates a significant difference at the 0.05 level $(0.01 \leq p<0.05)$ and ${ }^{(* *}{ }^{(*)}$ indicates a highly significant difference at the 0.05 level $(p<0.01)$. '-' is reduced.

extends $6.22 \mathrm{~cm}$, and side length extends $4.23 \mathrm{~cm}$. Appropriate increases in back length and side length can satisfy the sports needs of human upper limbs. As for the lower body's movement, the outer side waist length extends $5.33 \mathrm{~cm}$, while the front centre line of leg extends $6.05 \mathrm{~cm}$.

\subsection{Ease Discussion}

Table 6 illustrates the change range for major measurement sizes in each posture. The maximum values are very important for the design of protective clothing. It can be seen that proper reduction in the small shoulder width can help increase the human body's upper limbs. Back length and back width are two active factors in the design of upper outer garments. The back

Table 6: Variation range for major body measured sizes (unit: $\mathrm{cm}$ )

\begin{tabular}{lclc}
\hline Measured Size & Variation Range & Measured Size & Variation Range \\
\hline Small Shoulder Width & $-1.62 \sim-0.18$ & Back Length & $0.15 \sim 6.22$ \\
Back Width & $3.59 \sim 7.84$ & Side Length & $-2.13 \sim 4.25$ \\
Bust & $2.39 \sim 7.98$ & Front Median Length & $-4.66 \sim 7.59$ \\
Hip & $0.07 \sim 7.17$ & Rear Median Length & $-0.90 \sim 11.87$ \\
Thigh Girth & $0.00 \sim 3.14$ & Outer Side Waist Length & $-4.95 \sim 5.33$ \\
Mid-thigh Girth & $-0.06 \sim 1.79$ & Front Centre Line of Waist to Ankle & $0.56 \sim 6.63$ \\
Knee Girth & $-0.02 \sim 4.07$ & Back Centre Line of Waist to Ankle & $-0.81 \sim 5.62$ \\
Armscye Girth & $-2.37 \sim 1.49$ & Inner Length of Leg & $-0.66 \sim 0.81$ \\
Upper-arm Girth & $0.84 \sim 1.98$ & Rear Armpit Point to Wrist & $3.70 \sim 8.06$ \\
Elbow Girth & $-1.57 \sim 3.27$ & & \\
\hline
\end{tabular}


width ease value is at least $7.84 \mathrm{~cm}$. Otherwise, the horizontal direction of the entire back is restricted by the back expansion posture. The ease of the back length needs at least $6.22 \mathrm{~cm}$ to prevent neck buckling during flexion or squatting. For hip, thigh and knee, the ease design of these areas determines whether the body can lift the leg normally when running. Increasing the side length and arm inside length can satisfy the amount of extending when arms are lifted. In the process of plate-making, the length of upper outer garment needs to add $11.87 \mathrm{~cm}$, while the pants need to meet the requirements of skin extension by $5.33 \mathrm{~cm}$. Especially in the case of special protective clothing, it avoids contact with harmful gases or substances during operations.

\section{Conclusions}

Using a 3D scanner to obtain skin changes in different postures of the human body offers better accuracy and practicality. The measurement results can provide a scientific guideline for the ease design of protective clothing. We can reach the following conclusions based on the research and analysis of this paper.

(1) In the case of the upper body's movement, the change in the back is significant. With the back width stretching $7.84 \mathrm{~cm}$ and the back length stretching $6.22 \mathrm{~cm}$, the back area's ease design should meet the needs of skin stretching.

(2) By increasing the length of inside line and side line of the arms or reducing the small shoulder width, the mobility of the upper limbs can be improved.

(3) The expansion in the elbow and knee joints is significant. It can be improved by designing darts or pleats.

(4) The upper outer garment length should be increased by $11.87 \mathrm{~cm}$ to avoid a lack of length caused by squatting or raising the arms.

(5) The waist to hip size still needs to be increased to avoid upward pulling, although vertical stretching near the hip circumference is not large.

To optimize the design of the protective clothing structure, the skin changes under specific movements should be taken into consideration. The specific ease design of clothing still needs to consider the design of the plate-making, the elasticity of the fabric etc.

\section{Acknowledgements}

The authors wish to acknowledge the Beijing Key Laboratory of Clothing Ergonomics and Innovation Functional Design program (KYTG02170202).

\section{References}

[1] Zhang Y. Analysis of protective clothing design factors. GuangXi Light Industry: 2010, 26(05): 91-93.

[2] Zhang XH, Wang YY, Li J, Zhang WB. Influence of protective clothing structure design on dressing comfort. Journal of Textile Research: 2009, 30(06): 138-144. 
[3] Huck J, Kim Yet al. Protective overalls evaluation of garment design and fit. International Journal of Clothing Science and Technology: 1997, 9(1): 45-61.

[4] Mullet KK. The effect of shoulder position on four sleeve/bodice structure. Blacksburg, USA, Virginia State University: 1991.

[5] Guan Y. Quantitative study of upper body posture changes and clothing structure. Tianjin University of Science and Technology: 2013.

[6] Wang YJ, Mo BX, Li Y et al. Effects of waist and lower limb exercises on loose design of clothing. Journal of Textile Research: 2010, (3): 92-97.

[7] Xiao LZ. Research on the relationship between clothing local looseness and human comfort. Tianjin Textile Technology: 2010(04): 45-47.

[8] Yuan F, Yuan GL, Wang CY. The relationship between upper limb movement and clothing structure. Journal of Textile Research: 2006(07): 40-43.

[9] Li J, Guan WJ, Wei HF. Application and development of performance estimation of functional protective clothing [J]. China Personal Protective Equipment: 2005(6): 22-25

[10] Ashdown SP. An exploratory study of the validity of visual fit assessment from three-dimensional scans [J]. Clothing Textile Research Journal: 2010, 28(4): 263278

[11] Wang Y Y, Zong YJ, Li J. Thermal protective performance of home-made new fabrics for firefighter protective clothing [J]. China Textile Leader: 2008(8): 98-100.

[12] Liu Y, Liu YM. Research on comfort of sportswear under condition of maximal training volume [J]. Physical Science: 2004, 24(11): 71-78.

[13] Li Y, Fu XL, Shang HC. Study on 3D human body measurement methods. Journal of Textile Research: 2001(04).

[14] Liu RP. Clothing pattern making theory and technology [M]. Beijing: China Textile \& Apparel Press: 2005: 33-37.

[15] ISO 8559, 1989. Garment Construction and Anthropometric Surveys: Body Dimensions, first ed. ISO. 